Editorial

\title{
Considerations in delivering an expert opinion
}

Volume 3 Issue 4 - 2016

\section{Editorial}

In the litigious environment of today, disputes between two or more companies can occur and require legal representation to help resolve the dispute. These disputes can arise from accidental or intentional shipment of products that do not meet specifications, leading to market withdrawals, recalls, lost revenues and unanticipated costs. Disputes can result from consumer illnesses coming from consumption of adulterated foods, where the identity and microbiological characterization of the specific food is not understood completely. Disputes can occur when manufacturing contracts are not specific enough to avoid different interpretations, such as what constitutes an adequate quality control program, or when patent infringement is thought to have occurred. Regardless of the type of dispute, experts, such as those in the field of microbiology, may be requested to provide and expert opinion for one or the other side of the dispute.

An expert opinion, for example, representing a plaintiff or defendant in a law suit, requires thought in evaluating whether it is appropriate to provide such an opinion. The most obvious factors that might prevent providing an opinion are whether there has been involvement with either the plaintiff or defendant previously and whether there has been a personal relationship with employees of companies that are involved in the dispute. Another disqualifying factor might be if the individual requested to prepare an opinion has any financial interest in the outcome of the proceedings, for example, if there were stock holdings in either company. Although it may be tempting to accept the request to prepare an opinion for financial or status reasons, if the person receiving the request is not an expert in the field under question, the lack of expertise is likely to be exposed during depositions or trial.

Perhaps the most important consideration before accepting the request to prepare an expert opinion is whether the expert opinion can be supported by the facts of the dispute, that is, in good conscious is it possible to believe in the expert opinion that will be written. It is important that in writing the opinion, it reflects the facts and can support the legal position for the entities requesting the opinion. To fully understand whether an expert opinion can meet the above requirements, it may be necessary to tentatively accept the offer to prepare an opinion, with the caveat that after reviewing all of the facts, a supporting opinion may not be possible. It is important to believe in the opinion and be prepared to defend the opinion since the opposing party in the dispute likely will have experts that will read the expert opinion and provide an expert response to the opinion.

To accept the request to prepare an expert opinion, the expert should have the technical competencies to address the issues in the

\author{
Robert A Seward \\ Department of Food safety and quality, Seward Global \\ Consulting, USA \\ Correspondence: Robert A Seward, Seward Global \\ Consulting, I I I 5th Street SE, Washington DC, 20003, USA, Tel \\ 402-66I-9096, Email skipdee@gmail.com \\ Received: June 29, 2016 | Published: July 0I, 2016
}

dispute and know where the scientific data resides to support the opinion. Often the opinion may cite references; although typically the expert opinion is no a literature review. Only key points may need to be supported with a published reference. In accepting the request to prepare an expert opinion, the expert must be willing to work with attorneys or other parties to edit and modify the opinion. While not changing the basic content of the opinion, such changes often reflect the vocabulary and needs of the attorneys representing their client. Flexibility is necessary to ensure the opinion is written in an expeditious manner that meets the requirements of all interested parties.

If fortunate, a well-written expert opinion can expedite the resolution of the dispute without a trial. The opposing parties may examine the opinions on both sides and determine that the strength of one, presumably and hopefully the correct opinion, would certainly lead to a specific decision by a judge, mediator or jury. All expert opinions are confidential amongst the parties involved in the dispute. No information regarding the dispute shall be discussed with persons not approved by the supporting attorney during the development and finalizing of the expert opinion.

\section{Acknowledgments}

None.

\section{Conflicts of interest}

Author declares there are no conflicts of interest. 